Rey E. La dieta y el síndrome de intestino irritable ¿no pero sí? ¿sí pero no? An Med Interna (Madrid) 2004; 21: 575-576.

La calidad de vida es un aspecto fundamental para todos los que vivimos en el mundo occidental y, sin duda, la salud es un bien insustituible para cualquiera de nosotros (1). Los trastornos funcionales digestivos no suponen una amenaza vital pero realmente son devastadores para la calidad de vida en muchos pacientes (2). Actividades que son naturales y se presupone que van a discurrir de forma inadvertida o incluso placentera, como es el comer, se convierten en una actividad penosa y llena de miedo al que ocurrirá después. Esta es la percepción diaria de muchos de nuestros pacientes con síndrome de intestino irritable (SII). Preguntas como ¿es el síndrome de intestino irritable un problema derivado de la alimentación que hago?, ¿qué debo comer?, o ¿qué debo evitar comer?, son habituales en la consulta. Hoy por hoy, todavía nos falta una respuesta adecuada para estas preguntas, aunque cada vez es más la información que vamos acumulando. El estudio de Aller y cols. (3) que se publica en este número de Anales de Medicina Interna aporta varios datos interesantes y nos da la oportunidad para reflexionar en que punto nos encontramos.

¿Tiene la alimentación una participación fisiopatológica en el síndrome de intestino irritable? Si aceptamos que el síndrome de intestino irritable tiene un origen multifactorial en el que se integran factores biológicos (sensibilidad, motilidad), (4,5) psicosociales (6) e inmunoalérgicos (7) es evidente que la alimentación juega un papel, puesto que es $a$ priori el proveedor de estímulos al sistema digestivo para generar respuesta sensitivas y reacciones motoras, es fuente exógena de antígenos y es una actividad diaria que fácilmente puede influir o estar influida por factores de la esfera psicosocial. La pregunta práctica evidente es ¿cuál es el papel real que juega y cuál es la dieta que debemos recomendar?

El trabajo de Aller y cols. (3) nos muestran que los pacientes con SII hacen una dieta que no se ajusta a las recomendaciones aceptadas en los EE.UU., aunque esto no necesariamente indica un papel real. Es bien conocido que la ingesta de grasas se asocia con aumento de los reflejos motores (8) y de la sensibilidad, (9) por lo que sería a priori sencillo señalar un exceso de grasas en la dieta como origen del SII. Sin embargo, ¿hasta qué punto las desviaciones identificadas no son un reflejo de desviaciones en la dieta de la población general? Lo cierto es que si comparamos la distribución calórica, los resultados de Aller y cols. (3) indican una distribución muy similar a la media de la población española, al menos a los datos obtenidos por la Encuesta Nacional de Nutrición y Alimentación (ENNA 91), por lo que el papel real que juegan estas desviaciones es claramente incierto, al menos visto desde el punto de vista cuantitativo. Es llamativo, aunque no comentado por los autores la baja ingesta calórica total (1.646 cal/día frente a 2.634 cal/día en ENNA, que probablemente es un reflejo de la exarcebación de los síntomas por la ingesta, hecho constatado en varios estudios (10).

Muy interesantes son los resultados aportados respecto a la ingesta de fibra. La relación entre el SII y la ingesta de fibra es muy controvertida, (11) tanto desde el punto de vista fisiopatológico ( $i$ una menor ingesta de fibra se relaciona con el SII?) como desde el punto de vista terapéutico (¿son los suplementos de fibra beneficiosos?).

Los resultados de Aller y cols. (3) claramente apoyan un papel para la fibra. En primer lugar, la cantidad de fibra ingerida comunicada es muy inferior a la media española (7,5 g/día aproximadamente frente a $21 \mathrm{~g} /$ día de media según la ENNA), muy por debajo de los más de 25 gr/día recomendables). El hecho de identificar una correlación inversa entre la severidad de los síntomas y la ingesta de fibra, señalando además a la fibra insoluble como la principal responsable es sin duda la aportación más relevante. Hay diferencias importantes entre la fibra soluble e insoluble en sus acciones sobre el colon. Mientras la fibra insoluble tan solo aumenta la masa fecal, la fibra soluble es además degradada por la flora intestinal y puede contribuir a la formación de gas, incrementando la masa de bacterias colónicas. No obstante, una reciente revisión desaconseja la fibra insoluble (12), por lo que se hace patente la necesidad de nuevos estudios, no sólo que evalúen el beneficio real del incremento de la fibra sino también (y probablemente sobre todo) que identifiquen qué subgrupo de pacientes se benefician y cuales no. Entretanto, estudios como el que se 
presenta en este número de Anales de Medicina Interna contribuyen notablemente a identificar los puntos en los que debemos centrarnos para avanzar en nuestro conocimiento del Síndrome de Intestino Irritable.

\section{E. REY}

Servicio de Aparato Digestivo. Hospital Clínico San Carlos. Madrid

\section{Bibliografía}

1. Rey E. Medir la Calidad de vida en España. Rev Esp Enf Digest 2001; 93: 687-689.

2. Hahn BA, Kirchdoerfer LJ, Fullerton S, Mayer E. Patient-perceived severity of irritable bowel syndrome in relation to symptoms, health resource utilization and quality of life. Aliment Pharmacol Ther 1997; 11: 553-559.

3. Aller R, de Luis DA, Izaola O, La Calle F, del Olmo L, Fernandez L, Arranz T. Patron de ingesta en un grupo de pacientes con síndrome de intestino irritable: Relacion de la ingesta de fibra con los síntomas. An Med Interna (Madrid) 2004; 21: 577-580.

4. Rey E, Díaz-Rubio M. Prevalencia de hipersensibilidad en el síndrome de intestino irritable y sus subgrupos clínicos. Rev Esp Enferm Dig 2002; 94: 247-232.

5. Chey WY, Jin HO, Lee MH, Sun SW, Lee KY. Colonic motility abnormality in patients with irritable bowel syndrome exhibiting abdominal pain and diarrhea. Am J Gastroenterol 2001; 96: 1499-1506.

6. Drossman D. Do psychosocial factors define sympton severity and

patient status in irritable bowel syndrome? Am J Med 1999; 107 (5A) 41S-50S.

7. Gui XY. Mast cells: a possible link between psychological stress, enteric infection, food allergy and gut hypersensitivity in the irritable bowel syndrome. J Gastroenterol Hepatol 1998; 13: 980-989.

8. Simren M, Abrahamsson H, Bjornsson ES. An exaggerated sensory component of the gastrocolonic response in patients with irritable bowel syndrome. Gut 2001; 48: 20-27.

9. Accarino AM, Azpiroz F, Malagelada JR. Modification of small bowel mechanosensitivity by intestinal fat. Gut 2001; 48: 690-695.

10. Simren M, Mansson A, Langkilde AM, Svedlund J, Abrahamsson H, Bengtsson U, Bjornsson ES. Food-related gastrointestinal symptoms in the irritable bowel syndrome. Digestion 2001; 63: 108-115.

11. Francis CY, Whorwell PJ. Bran and irritable bowel syndrome: time for reappraisal. Lancet 1994; 344: 39-40.

12. Burden S. Dietary treatment of irritable bowel syndrome: current evidence and guidelines for future practice. J Hum Nutr Diet 2001; 14: 231-241. 